\title{
EL ENFOQUE PRAXEOLÓGICO, ARTICULACIÓN ENTRE CONOCIMIENTO, PRÁCTICA Y TRANSFORMACIÓN SOCIAL*
}

\author{
THE PRAXEOLOGICAL APROACH, ARTICULATION BETWEEN \\ KNOWLEDGE, PRACTICE AND SOCIAL TRANSFORMATION
}

\author{
DIANA LOPERA MONTOYA** \\ RICARDO ANDRÉS GUTIÉRREZ GARCÍA***
}

Recibido: 20 de agosto de 2017 - Aceptado: 20 de septiembre de 2017 - Publicado 31 julio de 2018 DOI: $10.24142 /$ raju.v13n26a5

\section{Resumen}

La Corporación Universitaria Minuto de Dios (UNIMINUTO), en su misión de aportar a la transformación de las realidades sociales, plantea en su enfoque educativo la estrategia que procura articular la teoría con la práctica — praxeología-. Por ello, la investigación formativa

\footnotetext{
* $\quad$ El presente artículo es resultado de la investigación "Organización Comunitaria en la Comuna 11 de Bello. Experiencias de participación y articulación a la proyección social en UNIMINUTO” que fue realizada durante el segundo semestre de 2015 hasta el primer semestre de 2017.

** Trabajadora Social de la Corporación Universitaria Minuto de Dios (UNIMINUTO), Magíster en Gerencia Social de la Escuela de Administración, Universidad EAFIT, docente de tiempo completo de la Corporación Universitaria Minuto de Dios (UNIMINUTO). Correo electrónico: dlopera1@uniminuto.edu.co

*** Licenciado en Pedagogía Reeducativa, Especialista y Magíster en Intervenciones Psicosociales, Universidad Luis Amigó, docente de tiempo completo de la Corporación Universitaria Minuto de Dios (UNIMINUTO). Correo electrónico: rgutierrezg@uniminuto.edu.co
} 
es un planteamiento que viabiliza que tanto estudiantes y docentes vivan y sientan realmente el conocimiento y que, a su vez, articulen e incidan en las comunidades. A este respecto, presentaremos una experiencia que da cuenta del enfoque praxeológico. La intención de UNIMINUTO es, entonces, que el conocimiento transforme y genere reflexiones y acciones de cara a las necesidades de los contextos. La universidad de hoy no puede ni debe sustraerse a una mirada sobre el territorio, sus problemáticas y potencialidades, por tanto, estudiantes y docentes deben constituirse en conectores de espacios académicos con la realidad social.

Palabras clave: organización comunitaria, participación comunitaria, praxeología.

\section{Abstract}

The University Minute of God Corporation, UNIMINUTO, in its mission to contribute to the transformation of social realities, raises in its educational approach the strategy that seeks to articulate theory with practice - praxeology - . For this reason, the formative research is an approach that makes viable that both students and teachers live and feel the knowledge, and at the same time articulate and influence the communities. In this regard, we would present an experience that gives an account of the praxeological approach. The intention of UNIMINUTO is that knowledge transforms and generates reflections and actions in face of the needs of the contexts. Today's university cannot and should not take a look at the territory, its problems and potentialities, therefore, students and teachers must become connectors of academic spaces with the social reality.

Keywords: community organization, community participation, praxeology. 


\section{INTRODUCCIÓN}

El siguiente escrito surge de la realización de la investigación "Organización Comunitaria en la Comuna 11 de Bello. Experiencias de participación y articulación a la proyección social en UNIMINUTO". La reflexión nace tras comprender el potencial que tiene la comunidad aledaña para generar conocimiento y como la universidad, desde sus objetivos misionales y académicos, debe desarrollar comprensiones de los procesos comunitarios.

Esta investigación se orientó bajo el paradigma histórico-hermenéutico, con énfasis en la etnografía, ya que esta:

desagrega lo cultural en objetos más específicos, tales como la caracterización e interpretación de pautas de socialización, la construcción de valores, el desarrollo y las expresiones de la competencia cultural, el desarrollo y la comprensión de las reglas de interacción, entre otros (Sandoval, 2002, p. 61),

y busca comprender e interpretar la realidad a partir del sujeto, para poder hacer un reconocimiento de la realidad que construye cada organización comunitaria por medio de sus experiencias, relaciones e interacciones sociales. Además, con dicho paradigma se pretende generar preguntas, con el fin de abrir nuevos procesos investigativos y búsquedas para proyectar sujetos que sean partícipes de la investigación.

La investigación se desarrolló bajo el enfoque cualitativo, haciendo énfasis en la etnografía, ya que fue un componente importante pues está basada en:

Un análisis de datos que involucra la interpretación explícita de los significados y funciones de las acciones humanas, producto que toma la forma de descripciones y explicaciones verbales principalmente, con un rol de la cuantificación y el análisis subordinado al máximo (Sandoval, 2002, pp. 61-62).

Donde se le dio importancia a las historias de vida y sociales de la comunidad con el fin de analizar las vivencias y experiencias de cada una de las organizaciones comunitarias de la comuna, la cual ayudó a identificar la participación que hay dentro de las mismas. 
Para el desarrollo de esta investigación se realizaron entrevistas tipo encuesta, que "buscan hacer equivalentes las categorías de análisis empleadas con el propósito de facilitar los análisis comparativos" (Sandoval, 2002, p. 139). Asimismo, se tomó una muestra no probabilística e intencional con base en los criterios de conveniencia para la investigación y de los objetivos planteados, siendo muy útil para las investigaciones exploratorias y reflexivas la estrategia "bola de nieve", con el fin de localizar organizaciones y que estas nos llevaran a otras de forma paulatina.

También es importante mencionar que se trabajó con una perspectiva comunitaria, donde se le da relevancia a la historia de la comunidad y cómo los seres humanos la creamos. Es la importancia que las personas le dan a sus bienes y a su historia por medio de la experiencia y la participación.

Comprendida la ruta metodológica que orientó la investigación, se pasará a evidenciar algunos de los hallazgos en dos categorías gruesas: el territorio y las organizaciones sociales y comunitarias, en las cuales se encontrarán asuntos como la composición de las organizaciones, la generación de biodesarrollo y los procesos de participación, para luego finalizar en la articulación investigación-praxeología, conocimiento-práctica y transformación social.

\section{EL TERRITORIO}

La Comuna 11 del municipio de Bello, en su espacio territorial, está comprendida entre la carrera 43B, entre la calle 31 y 32 , y la calle $21 \mathrm{C}$ entre carrera 40A y 40 (Alcaldía de Bello, 2009, p. 132). Actualmente, se encuentra conformada por ocho barrios, siendo estos La Gabriela, Belvedere, Acevedo, Zamora, Alpes del Norte, Santa Rita, Montes Claros y Zona Industrial \#7. La población oscila alrededor de 22.958 habitantes, según datos establecidos en el Plan de Desarrollo Municipal para el periodo de 2012 a 2015. Sus límites son: al norte con Caños las Velas; al oriente con el perímetro urbano; al sur con la quebrada Negra o Seca (municipio de Medellín) y al occidente con el río Aburrá (Alcaldía de Bello, 2012, p. 16).

En tal sentido, es pertinente señalar que los límites que separan a la Comuna 11 de Bello con el municipio de Medellín son difusos, debido a su corta distancia dividida únicamente por la quebrada La Seca. Adicional a lo anterior, se evidencia una confusión entre los habitantes, debido a la actualización en la numeración de las comunas en la que Fontidueño (anterior- 
mente Comuna 9) pasa a ser Comuna 10, a la división del sector de Niquía (anteriormente Comuna 8) que adiciona una comuna más, dando paso a la Comuna 11, como se evidencia a continuación.

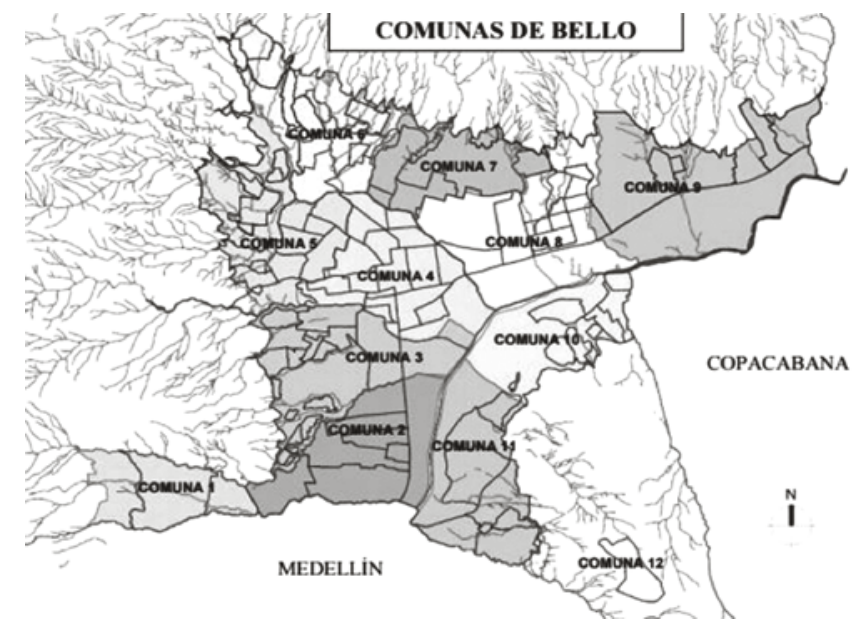

Figura 5.1 Mapa comunas de Bello

Fuente: Oficina de Gestión del Riesgo, Plan municipal de

Gestión del riesgo de desastres versión 1 (Municipio de Bello, 2015).

Es de anotar, que la investigación pudo demostrar que varias personas del sector no reconocen específicamente la pertenencia al municipio de Bello, debido a que la construcción de territorio que históricamente se ha forjado entre ellos tiene al municipio de Medellín como referente más cercano para el desarrollo de su comunidad. En palabras de Sorre (citado en Vargas, 2012):

La geografía debería estudiar las formas por las cuales los hombres organizan su espacio, considerando el espacio como la morada del hombre y para ello desarrolló el concepto de hábitat, el cual usa indistintamente con el de ecúmene. El hábitat en Sorre es el área habitada por una comunidad, la cual la ha organizado, por lo tanto se trata de una forma humanizada del espacio que expresa sus múltiples relaciones entre el ser humano y el ambiente que lo envuelve (p. 315). 
Lo anterior conecta, precisamente, con lo que sucede en la Comuna 11, dado que si bien existen unos límites constituidos y declarados legalmente las personas que allí habitan la nombran y la viven de acuerdo con sus propias construcciones y necesidades, que cultural e históricamente han forjado.

\section{EL TERRITORIO Y LAS ORGANIZACIONES SOCIALES Y COMUNITARIAS}

El territorio, como espacio que alberga las organizaciones sociales y comunitarias, fue el foco central de la investigación.

El espacio es un conjunto concreto, objetivo de localizaciones materiales de naturaleza muy variada que involucra actividades humanas como el uso de la tierra, urbanas, topográficas, biogeográficas, de servicios, de hábitats y de relaciones muy diversas. Estas actividades se localizan y se estructuran en organizaciones espaciales, de extensión variada que comprenden escalas desde el nivel local al mundial, las cuales son conectadas por flujos de energía y materiales (Vargas, 2012, p. 321).

Es así como la organización comunitaria se ha concebido como un acápite, un mecanismo, una herramienta más para lograr el desarrollo del territorio comunitario y la solución de necesidades particulares y colectivas. En este contexto se entiende la organización comunitaria como un "mecanismo que facilita la intervención en asuntos públicos y permite formar redes para construir el desarrollo colectivo, determinar acciones a emprender para confrontar determinada situación y modificar estructuras" (Usma, 2005, p. 9).

En la Comuna 11 se pudieron identificar alrededor de veintisiete organizaciones sociales y comunitarias, en donde se articularon las categorías de territorio y comunidad con el concepto de biodesarrollo local, el cual, a su vez, comprendía unas subcategorías que se nombran en la siguiente tabla. 
El enfoque praxeológico, articulación entre conocimiento, práctica y transformación social

Tabla 5.1 Subcategorías del desarrollo local y comunitario

\begin{tabular}{|l|l|}
\hline \multicolumn{1}{|c|}{ Categoría } & \multicolumn{1}{c|}{ Subcategorías } \\
\hline \multirow{4}{*}{ Biodesarrollo local y comunitario } & Condiciones de vida \\
\cline { 2 - 2 } & Empoderamiento \\
\cline { 2 - 2 } & Situaciones problemáticas \\
\cline { 2 - 2 } & Configuración como actores políticos \\
\cline { 2 - 2 } & Ecosistema \\
\cline { 2 - 2 } & Educación para el "saber convivir" \\
\hline
\end{tabular}

Fuente: elaboración propia.

El biodesarrollo local y comunitario se comprende como:

Un modelo alternativo al desarrollo económico y con él, entonces, a la idea de crecimiento económico. Es un modelo alternativo a la economía de mercado como un modelo de vida (antes que, simplemente, un modelo económico). La idea de base es que no por cambiar los modelos económicos se cambia la forma de vida de los seres humanos, mientras que lo contrario sí puede suceder. La tesis, como se aprecia, es bastante más radical, si bien aquí queda expuesta de forma aún muy filosófica (Maldonado, 2012).

Las organizaciones sociales y comunitarias que hacen parte del biodesarrollo de la Comuna 11 se exponen en la tabla 5.2. 
Tabla 5.2 Caracterización organizaciones sociales

\begin{tabular}{|c|c|c|}
\hline INSTITUCIÓN & OBJETO SOCIAL & SERVICIO QUE PRESTA \\
\hline $\begin{array}{l}\text { Hogar Infantil } \\
\text { Gato con Botas }\end{array}$ & $\begin{array}{l}\text { Institución dedicada a la for- } \\
\text { mación de niños y niñas }\end{array}$ & $\begin{array}{l}\text { Atención integral a población } \\
\text { infantil } \\
\text { Garantizar la educación de cali- } \\
\text { dad de niños y niñas }\end{array}$ \\
\hline $\begin{array}{l}\text { Grupo Scout } 137 \\
\text { Alcalá }\end{array}$ & $\begin{array}{l}\text { Contribuir a la educación de } \\
\text { los jóvenes, a través de un sis- } \\
\text { tema de valores basados en la } \\
\text { Promesa y la Ley Scout, para } \\
\text { ayudar a construir un mundo } \\
\text { mejor donde las personas son } \\
\text { autosuficientes como indivi- } \\
\text { duos y juegan un papel cons- } \\
\text { tructivo en la sociedad }\end{array}$ & \begin{tabular}{|l} 
Espacio formativo de jóvenes \\
\end{tabular} \\
\hline $\begin{array}{l}\text { Fundación } \\
\text { UNBOUND }\end{array}$ & $\begin{array}{l}\text { Acompañamiento para niños, } \\
\text { niñas, adolescentes y adulto } \\
\text { mayor mediante programas } \\
\text { de atención integral y acom- } \\
\text { pañamiento en el ciclo de } \\
\text { vida de los mismos. }\end{array}$ & $\begin{array}{l}\text { Apoyo a los procesos forma- } \\
\text { tivos de niños y niñas con ac- } \\
\text { tividades escolares y extracu- } \\
\text { rriculares. Acompañamiento a } \\
\text { niños, niñas y adolescentes en } \\
\text { sus proyectos de vida. Apadri- } \\
\text { namiento a niños, niñas y adul- } \\
\text { to mayor. Talleres con madres } \\
\text { de familia en el manejo de la } \\
\text { economía familiar. Talleres con } \\
\text { niños y niñas sobre valores }\end{array}$ \\
\hline $\begin{array}{l}\text { Hermanas de } \\
\text { la Providencia } \\
\text { Social Cristiana } \\
\text { sede Hogar San } \\
\text { Luis Gonzaga }\end{array}$ & $\begin{array}{l}\text { Institución que busca forta- } \\
\text { lecer el proyecto de vida en } \\
\text { adolescentes, niños y niñas en } \\
\text { situación de vulnerabilidad }\end{array}$ & $\begin{array}{l}\text { Atención integral a niño, ni- } \\
\text { ñas y adolescentes en jornadas } \\
\text { diurnas. } \\
\text { Acompañamiento familiar me- } \\
\text { diante asesorías para la convi- } \\
\text { vencia y el mejoramiento de las } \\
\text { costumbres en el orden moral y } \\
\text { material. Formación en valores }\end{array}$ \\
\hline $\begin{array}{l}\text { Casa Cultural } \\
\text { Hermano Fran- } \\
\text { cisco (Hermanos } \\
\text { Capuchinos) }\end{array}$ & $\begin{array}{l}\text { Organización sin ánimo de } \\
\text { lucro que promueve procesos } \\
\text { de fortalecimiento comunita- } \\
\text { rio en el sector de La Orquí- } \\
\text { dea en el barrio La Gabriela }\end{array}$ & $\begin{array}{l}\text { Semilleros de refuerzo acadé- } \\
\text { mico. } \\
\text { Semilleros de arte: (baile, di- } \\
\text { bujo). } \\
\text { Semillero de manualidades con } \\
\text { adulto mayor y mujeres (costu- } \\
\text { rero). } \\
\text { Formación espiritual biblioteca }\end{array}$ \\
\hline
\end{tabular}


El enfoque praxeológico, articulación entre conocimiento, práctica y transformación social

(Continuación). Tabla 5.2 Caracterización organizaciones sociales

\begin{tabular}{|c|c|c|}
\hline INSTITUCIÓN & OBJETO SOCIAL & SERVICIO QUE PRESTA \\
\hline $\begin{array}{l}\text { Institución } \\
\text { Educativa La } \\
\text { Gabriela Eco } \\
\text { Club ATANA }\end{array}$ & $\begin{array}{l}\text { Promueve la vinculación de } \\
\text { estudiantes al grupo ecológi- } \\
\text { co con actividades extracurri- } \\
\text { culares que ayuden a reducir } \\
\text { los niveles de deserción es- } \\
\text { colar }\end{array}$ & $\begin{array}{l}\text { Concientización sobre el cuida- } \\
\text { do del ambiente }\end{array}$ \\
\hline $\begin{array}{l}\text { Centro de De- } \\
\text { sarrollo Integral } \\
\text { Frutos de Amor } \\
\text { (Compasión) }\end{array}$ & $\begin{array}{l}\text { Brindar atención a niños, ni- } \\
\text { ñas y adolescentes en condi- } \\
\text { ciones de vulnerabilidad del } \\
\text { municipio de Bello a través } \\
\text { de programas de apoyo al } \\
\text { proceso educativo, proyecto } \\
\text { de vida y fortalecimiento del } \\
\text { vínculo con las familias }\end{array}$ & $\begin{array}{l}\text { Refuerzo escolar y formación } \\
\text { en valores con niños, niñas y } \\
\text { adolescentes de } 5 \text { a } 18 \text { años. } \\
\text { Trabajo con las familias en for- } \\
\text { mación de pautas de crianza. } \\
\text { Escuela de padres. Acompaña- } \\
\text { miento psicosocial. }\end{array}$ \\
\hline $\begin{array}{l}\text { Fundación } \\
\text { Unámonos ISA } \\
\text { (Escuela Santa } \\
\text { Rita) }\end{array}$ & $\begin{array}{l}\text { Organización No Guberna- } \\
\text { mental (ONG) sin ánimo de } \\
\text { lucro y de trabajo voluntario, } \\
\text { conformada por empleados } \\
\text { de ISA y de sus filiales: INTER- } \\
\text { NEXA y XM, y de la Asociación } \\
\text { de Pensionados (ASOPEN). } \\
\text { Enfocada en el trabajo volun- } \\
\text { tario y solidario para la ges- } \\
\text { tión y participación en pro- } \\
\text { yectos sociales, en los campos } \\
\text { educativo, productivo y hu- } \\
\text { manitario, dirigidos a mejorar } \\
\text { la calidad de vida de grupos } \\
\text { vulnerables de la sociedad } \\
\text { colombiana y a promover la } \\
\text { responsabilidad social }\end{array}$ & $\begin{array}{l}\text { Apoyo psicosocial a niños y } \\
\text { niñas de instituciones educa- } \\
\text { tivas. Atención a las familias } \\
\text { mediante la escuela de padres. } \\
\text { Formación en valores y proyec- } \\
\text { to de vida }\end{array}$ \\
\hline $\begin{array}{l}\text { Los Elegidos una } \\
\text { Voz de Espe- } \\
\text { ranza }\end{array}$ & $\begin{array}{l}\text { Institución privada sin ánimo } \\
\text { de lucro que promueve ac- } \\
\text { tividades y tomas culturales } \\
\text { en barrios donde los jóvenes } \\
\text { están expuestos a factores de } \\
\text { vulnerabilidad }\end{array}$ & $\begin{array}{l}\text { Jornadas lúdico-recreativas } \\
\text { para el aprovechamiento del } \\
\text { tiempo libre. } \\
\text { Formación en valores y paz }\end{array}$ \\
\hline
\end{tabular}


(Continuación). Tabla 5.2 Caracterización organizaciones sociales

\begin{tabular}{|c|c|c|}
\hline INSTITUCIÓN & \begin{tabular}{|l|} 
OBJETO SOCIAL \\
\end{tabular} & SERVICIO QUE PRESTA \\
\hline $\begin{array}{l}\text { Casa de la Cultu- } \\
\text { ra Bethania }\end{array}$ & $\begin{array}{l}\text { Promover la participación de } \\
\text { la ciudadanía en torno al arte, } \\
\text { la cultura y el uso de las TIC, } \\
\text { posibilitando la apropiación } \\
\text { del espacio, la integración, } \\
\text { los procesos formativos y el } \\
\text { desarrollo comunitario }\end{array}$ & $\begin{array}{l}\text { Talleres artísticos: arte y pintu- } \\
\text { ra, baile, fotografía, clases de } \\
\text { guitarra. } \\
\text { Cursos complementarios: dise- } \\
\text { ño y elaboración de empaques, } \\
\text { decoración, arte country }\end{array}$ \\
\hline $\begin{array}{l}\text { Junta de Acción } \\
\text { Comunal Ace- } \\
\text { vedo }\end{array}$ & $\begin{array}{l}\text { La JAC de Acevedo se encar- } \\
\text { ga de representar a la comu- } \\
\text { nidad ante el gobierno y de } \\
\text { buscar el bienestar ciudada- } \\
\text { no, identificando las princi- } \\
\text { pales necesidades del sector. } \\
\text { Actualmente cuenta con } 189 \\
\text { socios }\end{array}$ & $\begin{array}{l}\text { Brigadas de salud y medio } \\
\text { ambiente, capacitaciones para } \\
\text { orientar a la comunidad en caso } \\
\text { de una emergencia }\end{array}$ \\
\hline $\begin{array}{l}\text { Junta de Ac- } \\
\text { ción Comunal } \\
\text { Zamora }\end{array}$ & $\begin{array}{l}\text { La JAC de Zamora se encarga } \\
\text { de representar a la comunidad } \\
\text { ante el gobierno y de buscar } \\
\text { el bienestar ciudadano, identi- } \\
\text { ficando las principales necesi- } \\
\text { dades del sector. Actualmente } \\
\text { cuenta con } 189 \text { socios }\end{array}$ & $\begin{array}{l}\text { Brigadas de salud y medio } \\
\text { ambiente, capacitaciones para } \\
\text { orientar a la comunidad en caso } \\
\text { de una emergencia }\end{array}$ \\
\hline $\begin{array}{l}\text { Junta de Acción } \\
\text { Comunal Santa } \\
\text { Rita }\end{array}$ & $\begin{array}{l}\text { No se pudo contactar a la or- } \\
\text { ganización }\end{array}$ & $\begin{array}{l}\text { No se pudo contactar s la orga- } \\
\text { nización }\end{array}$ \\
\hline $\begin{array}{l}\text { Escuela San } \\
\text { Nicolás }\end{array}$ & $\begin{array}{l}\text { No se pudo contactar a la or- } \\
\text { ganización }\end{array}$ & $\begin{array}{l}\text { No se pudo contactar a la orga- } \\
\text { nización }\end{array}$ \\
\hline $\begin{array}{l}\text { Iglesia Presbite- } \\
\text { riana Cumber- } \\
\text { land }\end{array}$ & $\begin{array}{l}\text { Formación del ser humano en } \\
\text { su restauración espiritual con } \\
\text { Dios, para servir a la comuni- } \\
\text { dad y al prójimo }\end{array}$ & $\begin{array}{l}\text { Articulación con la Alcaldía de } \\
\text { Medellín en el programa Buen } \\
\text { Comienzo, que funciona en las } \\
\text { instalaciones de la Iglesia y ha } \\
\text { contribuido a la disminución de } \\
\text { la desnutrición infantil }\end{array}$ \\
\hline $\begin{array}{l}\text { Iglesia Juan } \\
\text { Wesley }\end{array}$ & $\begin{array}{l}\text { Es una Iglesia Cristiana y } \\
\text { persigue como objetivo el } \\
\text { crecimiento espiritual y la re- } \\
\text { construcción del tejido social } \\
\text { entre las familias disfuncio- } \\
\text { nales o en alto riesgo, para } \\
\text { tener un verdadero impacto } \\
\text { social dentro de la comunidad }\end{array}$ & $\begin{array}{l}\text { Educación básica primaria para } \\
\text { los niños y niñas de la comu- } \\
\text { nidad }\end{array}$ \\
\hline
\end{tabular}


El enfoque praxeológico, articulación entre conocimiento, práctica y transformación social

(Continuación). Tabla 5.2 Caracterización organizaciones sociales

\begin{tabular}{|c|c|c|}
\hline INSTITUCIÓN & OBJETO SOCIAL & SERVICIO QUE PRESTA \\
\hline $\begin{array}{l}\text { Grupo de tercera } \\
\text { edad Alcalá }\end{array}$ & $\begin{array}{l}\text { Brindar bienestar al adulto } \\
\text { mayor, mediante terapias que } \\
\text { propendan por un hábito de } \\
\text { vida saludable }\end{array}$ & $\begin{array}{l}\text { Terapias recreativas y Motoras: } \\
\text { bailoterapias, con el fin de con- } \\
\text { trolar el sobrepeso en adultos } \\
\text { mayores }\end{array}$ \\
\hline $\begin{array}{l}\text { Grupo de tercera } \\
\text { edad Años Do- } \\
\text { rados }\end{array}$ & $\begin{array}{l}\text { Organización que trabaja con } \\
\text { el adulto mayor a partir de los } \\
55 \text { años. Su objetivo es lograr } \\
\text { que el adulto mayor tenga una } \\
\text { mejor calidad de vida, apren- } \\
\text { diendo a convivir a pesar de } \\
\text { las diferentes enfermedades } \\
\text { que presenta, sacándolo de } \\
\text { su rutina diaria y trabajando } \\
\text { para que el adulto mayor en- } \\
\text { tre al programa de la Alcaldía } \\
\text { de Bello y puedan recibir un } \\
\text { auxilio }\end{array}$ & $\begin{array}{l}\text { Atención a adultos de la tercera } \\
\text { edad mediante talleres, espa- } \\
\text { cios lúdicos-recreativos, esce- } \\
\text { narios deportivos y gimnasia } \\
\text { para el cuidado de la salud }\end{array}$ \\
\hline $\begin{array}{l}\text { Grupo juvenil } \\
\text { Dejando Huella }\end{array}$ & $\begin{array}{l}\text { No se pudo contactar a la or- } \\
\text { ganización }\end{array}$ & $\begin{array}{l}\text { No se pudo contactar a la orga- } \\
\text { nización }\end{array}$ \\
\hline $\begin{array}{l}\text { Junta Adminis- } \\
\text { tradora Local } \\
\text { Comuna } 11 \\
\end{array}$ & $\begin{array}{l}\text { No se pudo contactar a la or- } \\
\text { ganización }\end{array}$ & $\begin{array}{l}\text { No se pudo contactar a la orga- } \\
\text { nización }\end{array}$ \\
\hline $\begin{array}{l}\text { Grupo Juvenil } \\
\text { y Cultura pa'l } \\
\text { barrio }\end{array}$ & $\begin{array}{l}\text { No se pudo contactar a la or- } \\
\text { ganización }\end{array}$ & $\begin{array}{l}\text { No se pudo contactar a la orga- } \\
\text { nización }\end{array}$ \\
\hline $\begin{array}{l}\text { Plataforma } \\
\text { LGTBI }\end{array}$ & $\begin{array}{l}\text { Propiciar espacios de inclu- } \\
\text { sión de la población LGTBI } \\
\text { para abordar el tema de diver- } \\
\text { sidad sexual }\end{array}$ & $\begin{array}{l}\text { No se encuentra en funciona- } \\
\text { miento }\end{array}$ \\
\hline $\begin{array}{l}\text { Corporación Ca- } \\
\text { minos Unidos }\end{array}$ & $\begin{array}{l}\text { Capacitar a las madres cabeza } \\
\text { de familia con el fin de brin- } \\
\text { darles la posibilidad de ense- } \\
\text { ñarles un arte u oficio que les } \\
\text { permita mejorar su desarrollo } \\
\text { personal y calidad de vida, } \\
\text { dándoles la oportunidad de } \\
\text { generar ingresos económicos } \\
\text { para ellas y sus familias }\end{array}$ & $\begin{array}{l}\text { Capacitaciones a madres cabe- } \\
\text { za de familia en torno a un arte } \\
\text { u oficio, con temáticas como } \\
\text { cuerpo, mente y espíritu }\end{array}$ \\
\hline
\end{tabular}


(Continuación). Tabla 5.2 Caracterización organizaciones sociales

\begin{tabular}{|l|l|l|}
\hline INSTITUCIÓN & \multicolumn{1}{|c|}{ OBJETO SOCIAL } & \multicolumn{1}{c|}{ SERVICIO QUE PRESTA } \\
\hline $\begin{array}{l}\text { Parroquia San } \\
\text { Roberto Belar- } \\
\text { mino }\end{array}$ & $\begin{array}{l}\text { Servir a la comunidad y a la } \\
\text { evangelización dentro de la } \\
\text { Iglesia Católica, Apostólica y } \\
\text { Romana. }\end{array}$ & $\begin{array}{l}\text { Desarrollo de talleres en hoga- } \\
\text { res monoparentales, refuerzo } \\
\text { escolar, actividades de manejo } \\
\text { del tiempo libre (una JAC vin- } \\
\text { culada a la parroquia) }\end{array}$ \\
\hline JAC La Gabriela & $\begin{array}{l}\text { Junta en derechos y deberes } \\
\text { para llevar propuestas e ideas } \\
\text { y poder desarrollarlas en la } \\
\text { comunidad }\end{array}$ & $\begin{array}{l}\text { Talleres, seminarios, proyectos } \\
\text { comunitarios, educación am- } \\
\text { biental, formación a liderezas } \\
\text { en formación empresarial para } \\
\text { artesanías y producción pe- } \\
\text { queña }\end{array}$ \\
\hline Jóvenes en Red & $\begin{array}{l}\text { Propiciar, mediante la lúdica } \\
\text { y la recreación, espacios de } \\
\text { participación, transformación } \\
\text { y desarrollo a nivel del apren- } \\
\text { dizaje y el accionar social en } \\
\text { los jóvenes y niños del barrio }\end{array}$ & $\begin{array}{l}\text { Trabajo con la población infan- } \\
\text { til: vacaciones creativas, nove- } \\
\text { nas de navidad. } \\
\text { Participación de los jóvenes en } \\
\text { espacios relacionados con el } \\
\text { arte, la cultura y la lúdica }\end{array}$ \\
\hline
\end{tabular}

Fuente: elaboración propia.

En la tabla anterior no se enumeraron las madres comunitarias; ellas juegan un papel importante en el desarrollo del sector, no solo por el ejercicio de su labor, sino por la capacidad de organización que han gestado a través de los años desde su rol educativo y, en algunos casos, como lideresas comunitarias o miembros de la JAC o la JAL (entrevista personal con Gustavo Soto, promotor de la Casa de la Cultura Bethania, Bello, 2016).

Como demuestra la tabla 5.1, el objeto social de las organizaciones se centra en mejorar las condiciones de vida de la comunidad mediante la intervención comunitaria, con diferentes actividades (talleres, métodos lúdicos, conferencias, vacaciones recreativas, novenas de navidad, entre otras) que contribuyen a la integración de los pobladores de la Comuna 11 del municipio de Bello y que, dentro de esos aspectos, concretan el concepto de biodesarrollo local y comunitario.

En consonancia con lo anterior, las organizaciones sociales y comunitarias de la Comuna 11 generan biodesarrollo, el cual, a su vez, se ve reflejado en la capacidad de instaurar empoderamiento en los pobladores; definiendo empoderamiento como: 
la capacidad para decidir. Se relaciona de manera directa con el proceso de participación, quienes deciden son quienes participan; no todos tienen la misma condición en su participación para decidir, con lo cual salen a relucir las relaciones de poder, y la manera como estas determinan el proceso en torno a una problemática o necesidad (Bedoya y González, 2008, p. 196).

El empoderamiento guarda total y significativa relación con la participación, aspecto preponderante en los procesos sociales y comunitarios de la Comuna 11, ya que lo que se pudo encontrar en la investigación fue la presencia relevante de organizaciones que le apuestan al mejoramiento continuo de la calidad de vida de las personas que allí habitan.

Para profundizar en la caracterización de las organizaciones comunitarias de la Comuna 11 se eligieron catorce entidades, de las veintisiete encontradas en el proceso investigativo, en las cuales se realizó la aplicación de dos técnicas de recolección de información: encuesta y entrevista. Para dicha caracterización se establecieron las siguientes categorías y subcategorías.

Tabla 5.3 Categorías de análisis

\begin{tabular}{|c|c|c|}
\hline Categorías & \multicolumn{2}{|l|}{ Subcategorias } \\
\hline \multirow{9}{*}{$\begin{array}{l}\text { Organización } \\
\text { comunitaria }\end{array}$} & \multicolumn{2}{|c|}{ Identidad/Sentido de comunidad } \\
\hline & \multirow[t]{3}{*}{ Gestión externa } & $\begin{array}{l}\text { Conocimiento e incidencia en planes de de- } \\
\text { sarrollo }\end{array}$ \\
\hline & & $\begin{array}{l}\text { Autogestión, capacidad de gestión, ejecución } \\
\text { y sostenibilidad }\end{array}$ \\
\hline & & Redes y alianzas \\
\hline & \multirow[t]{3}{*}{ Gestión interna } & Estructura organizacional \\
\hline & & Manejo económico, financiero y empresarial \\
\hline & & Comunicación y participación comunitaria \\
\hline & \multirow[t]{2}{*}{ Redes sociales } & Individuos y colectivos \\
\hline & & Tejido social \\
\hline
\end{tabular}

Fuente: elaboración propia. 
Para la elección de las siguientes catorce organizaciones sociales se tuvieron en cuenta aspectos como objeto social, tiempo de constitución, comunidad beneficiada, entre otros; y uno que fue de vital importancia para la investigación: que las organizaciones dispusieran del tiempo para la aplicación de las técnicas de investigación, ya que varias de las que fueron elegidas no pudieron sacar un momento para la actividad. Las organizaciones que hicieron parte de la entrevista y la encuesta fueron:

- Centro de Desarrollo Integral Frutos de Amor

- Grupo Scout 137 Alcalá

- Hogar Infantil Gato con Botas

- JAC Zamora

- Jóvenes en Red

- Iglesia Juan Wesley

- Caminos Unidos

- Centro de Integración y Desarrollo Cultural Casa Bethania

- Grupo de tercera edad Alcalá

- JAC Acevedo

- Casa Cultural Hermano Francisco (Hermanos Capuchinos)

- JAC La Gabriela

- Iglesia Presbiteriana Cumberland

- Grupo de tercera edad Años Dorados

La comprensión de la información recolectada iniciará con la categoría de organización comunitaria. En esta se indagó por dos subcategorías, la gestión interna y externa; la primera relacionada con todo el andamiaje organizacional, es decir, conformación, toma de decisiones, gestión de la información, comunicación y manejo de conflictos. Y la segunda, la gestión externa, articulada al relacionamiento con otras organizaciones, conocimiento de los planes y proyectos municipales, trabajo en red con otros entes públicos y privados. 
Para dar inicio a la categoría de organizaciones comunitarias vale la pena decir que estas se definen porque "fundamentan su trabajo en objetivos comunes que saben que no pueden realizar o cumplir individualmente; entonces tienen que construir un proceso participativo para la búsqueda de soluciones y alternativas que ayuden a alcanzar lo propuesto" (Michaels, 2010, p. 176).

Valencia y Galeano (2011) describen la composición de las organizaciones así:

Las organizaciones sociales se componen de una gran diversidad de actores que usualmente buscan una meta común, un fin que las identifique, que les proporcione pertenencia. Pueden estar unidas en torno a una ideología, un conocimiento, un trabajo y un fin. Puede estar conformada por niños, jóvenes, adultos, madres, padres, mujeres, hombres, por profesionales, desplazados, emigrantes, religiosos y políticos (p. 62).

En ese sentido, las organizaciones comunitarias caracterizadas cuentan con un momento de fundación, donde establecen el número de socios o asociados, unos objetivos que son la ruta de funcionamiento, así como unos reglamentos y canales de comunicación. Para el caso de las organizaciones seleccionadas se pudo evidenciar que todas cuentan con un grupo de personas que hacen parte de la estructura, con un número representativo de integrantes, sobre todo en las JAC, iglesias y hogares de la tercera edad.

Lo anterior se contrasta con lo que plantean Vivas, Sarmiento y González (2015), cuando dice:

Las organizaciones sociales se conforman para agenciar un problema en la esfera pública, su naturaleza es congregar adeptos en torno a un interés que les articula mediante un conjunto de relaciones orientadas especialmente a convertir problemas sociales en problemas públicos y transformar el sentido y alcance de las intervenciones públicas (p. 79).

Es así como el objetivo o la misión que dio soporte a la creación de las organizaciones sociales responde a propuestas de corte social. Así se evidencia en las siguientes respuestas de las organizaciones sociales caracterizadas: 
- Sacar a los chicos de la pobreza espiritual, social y económica. Que sean personas de bien.

- Formar para la vida en valores cívicos, morales y humanos.

- Incentivar actividades lúdicas y recreativas.

- Promover el goce y la recreación en tiempo de vacaciones.

- Trabajar en el corazón de la gente.

- Ayudar a los profesionales a conseguir empleo; y también ayudar a salir adelante a la madre cabeza de hogar.

- Promover un desarrollo integral sostenible y sustentable orientador de sus logros y objetivos de liderazgo, para promover el desarrollo.

- Ser una junta en derechos y deberes para llevar propuestas e ideas y poder desarrollarlas en la comunidad.

- Traer personas a Jesús haciéndolas miembros de su familia, proveyéndoles formación para su crecimiento y madurez, encaminándolos hacia Cristo como modelo.

- Sacarlos de la rutina para un cambio de ambiente.

Para concretar lo que significa una organización social y lo que ello implica, se presenta el esquema desarrollado por Vivas, Sarmiento y González (2015), en el cual se establece que una de las características comunes de las organizaciones sociales es que tienen una estructura democrática y autogestionaria; además, contemplan unos fines particulares de funcionamiento, lo que se articula perfectamente a lo presentado en líneas anteriores.

En cuanto a la implementación de la estructura organizativa de las organizaciones sociales estas plantean unos criterios de ingreso, que van desde edad, hoja de vida, credo religioso, permanencia en el barrio, escolaridad y nivel de Sisbén, todos ellos de fácil cumplimiento y acceso a las personas interesadas. Además, las personas que quieran integrar una de estas organizaciones deben, libre y voluntariamente, hacer su solicitud; ello garantiza que no existe ninguna presión y que realmente anhelan su vinculación.

Asimismo, las organizaciones, en general, apuntan a que sus integrantes tengan la convicción puesta en el trabajo comunitario. Dos asuntos en concreto establecen para el mantenimiento de la estructura: que las personas 
deseen estar en ella y que sientan y vivan el trabajo comunitario. Los demás criterios de ingreso son fáciles de cumplir.

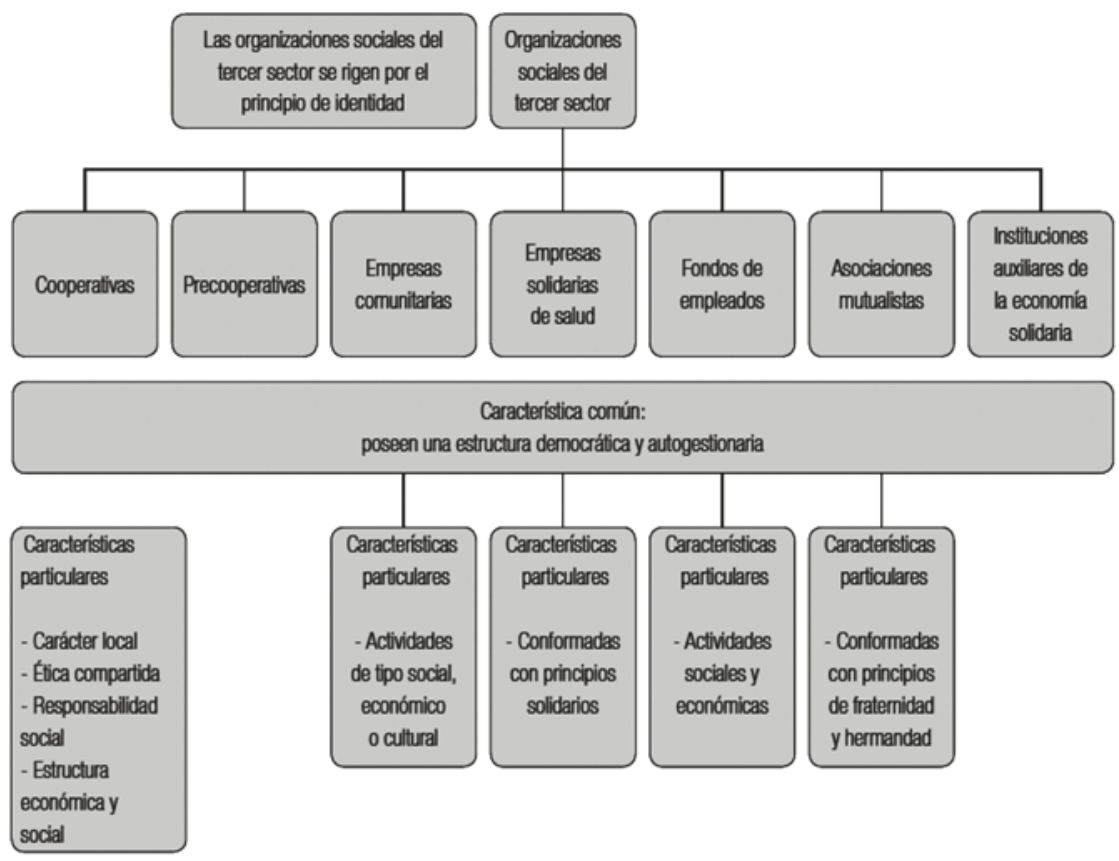

Figura 5.2 Tipos y características de organizaciones sociales

Fuente: Vivas, Sarmiento y González (2015b, p. 145).

Frente a la toma de decisiones, las organizaciones comunitarias son conscientes de lo que implica lo comunitario; por esta razón, las decisiones pasan por diversas formas participativas: junta, asamblea, reunión, comité; cualquiera que sea el nombre, todas son consecuentes en afirmar que la toma de decisiones es una actividad democrática y participativa. En tal sentido, cuando se indagó la forma de selección de los cargos de la organización la respuesta también se encaminó a utilizar los medios del consenso y la votación.

En cuanto a la estructura directiva, las organizaciones comunitarias, en general, cuentan con una, la cual es seleccionada por la vía democrática. Se preguntó por la periodicidad de reunión de dicho equipo directivo y las 
respuestas oscilaron entre semanal y mensualmente, unas pocas argumentaron hacerlo anualmente.

Lo anterior tributa, necesariamente, a la participación en el ámbito interno, la cual se ve fortalecida mediante procesos de formación y capacitación que se brindan en la organización, como talleres, diplomados, seminarios, programas de prevención, pedagogía, administración, promoción cultural y charlas educativas. Aunque algunas organizaciones afirman que, pese a tener los espacios de participación, no todos los miembros son activos, situación que puede estar sujeta al debilitamiento en la apropiación frente a objetivos comunes; y en tanto no haya participación representativa la toma de decisiones se delega a una minoría y los sujetos no asumirán como suyos los procesos de incidencia en la comunidad.

Para la gestión de la información llevan registros en actas (doce, de las catorce organizaciones, lo hacen); esto significa que le dan importancia a la historia de la organización y a la gestión del conocimiento, aspecto vital para los procesos que llevan a cabo, para la continuidad y la sistematización de la información.

Una organización comunitaria debe contar con normas o reglamentos y una estructura de cargos y responsabilidades que la orienten. En dichos ítems, todas las organizaciones cuentan con un documento que evidencia las normas y reglamentos, así como unos cargos o deberes que posibilitan su funcionamiento. Los más nombrados fueron:

- Coordinador

- Comité

- Junta directiva

La denominación era diferente en cada organización, pero la intención de cada una es darle estructura y orden a los procesos que llevan a cabo.

Para los temas de gestión de recursos las organizaciones tienen cuatro modalidades básicamente:

- Son subsidiadas por el Estado

- Hacen ahorros por medio de rifas o eventos que organizan

- Consiguen presupuesto por medio de donaciones

- Consiguen presupuesto por medio de créditos 
Las entidades subsidiadas por el Estado son, en su mayoría, las JAC, las cuales participan en proyectos o hacen gestión por medio de cartas a diversas secretarías de la Administración Municipal para su mantenimiento. Las demás organizaciones hacen eventos, rifas, ahorros y reciben donaciones para el sostenimiento y funcionamiento de las actividades que llevan a cabo. Muy pocas organizaciones hacen proyectos para gestionar recursos. Si bien cada una resuelve la consecución de estos de manera diversa sus ingresos son muy pocos para lograr la autosostenibilidad, asunto vital para el adecuado funcionamiento de las organizaciones. Así lo plantea Torres (citado en Cruz, Hernández, Llano, López, Pinzón y Rodríguez, 2008) cuando define la sostenibilidad como:

Condición resultante de que estas adelanten actividades para conseguir los resultados esperados relacionados con la solución de los problemas, satisfacción de necesidades y el fortalecimiento de los miembros para su desarrollo, garantizando que la organización tenga una vigencia y continuidad en sí misma en el tiempo, más allá de las adversidades, vicisitudes y transformaciones de los contextos locales y globales (p. 66).

Se puede observar entonces que la sostenibilidad articula procesos económicos, políticos, sociales y ambientales, una perspectiva holística y sistémica del funcionamiento de la organización; en tanto su foco debe estar puesto en comprender que si bien su objeto social es fundamental, la consecución de recursos para sostenerlo resulta imprescindible.

La sostenibilidad en las organizaciones sociales se define de cuatro formas, como lo argumenta Torres (citado en Cruz et al., 2008, p. 66):

- Sostenibilidad organizativa

- Sostenibilidad administrativa

- Sostenibilidad financiera

- Sostenibilidad social

La sostenibilidad organizativa es la forma como se construye la identidad y la interacción interna y externa. La sostenibilidad administrativa tiene que ver con la eficacia y la eficiencia de los procesos de la organización. La sostenibilidad financiera está relacionada con la realización de presu- 
puestos, donde costeen y planeen sus actividades y proyecten sus gastos en el tiempo, y la sostenibilidad social tiene que ver con el impacto positivo o negativo que generan las organizaciones en el entorno y en la comunidad donde realizan su labor (Torres citado en Cruz et al., 2008).

En concordancia con lo anterior, se podría afirmar que las organizaciones de la Comuna 11 están débiles en tal aspecto, sobre todo en el enfocado a la sostenibilidad financiera, ya que sus ingresos son muy precarios o dependen de entes externos para realizar sus actividades, lo que les genera cierta debilidad o inestabilidad.

En cuanto a la sostenibilidad organizativa, administrativa y social, las organizaciones tienen mayor fortaleza, ya que son conscientes de que su accionar a nivel interno y externo debe generar bien común.

Otro de los aspectos de la sostenibilidad en las organizaciones estudiadas tiene que ver con la importancia de hacerle planeación y seguimiento a las actividades y proyectos planteados, que en general intentan procurar bienestar y desarrollo a la comunidad; entendiendo el desarrollo no desde una postura meramente economicista, sino también desde una postura que incluye "la distribución social de los recursos productivos y del ingreso, a la movilidad social, a la participación cívica y al cambio de normas y de valores tradicionales" (Delgado citado en Vivas et al., 2015b, p. 155).

Dicho desarrollo se evidencia en la incidencia o impacto que tienen las organizaciones sociales, el cual está dado en una gran mayoría a nivel barrial, si mucho comunal; muy pocas afirman tener una cobertura municipal, sin embargo:

La incidencia es comprendida como la participación de las organizaciones de la sociedad civil en el proceso político (González, Villar, 2005, p. 2). Siendo las "Organizaciones de la Sociedad Civil" aquellas organizaciones que prestan servicios para el bienestar, y además son actores políticos, con la particularidad de que a diferencia de los partidos políticos su legitimidad no se fundamenta en la representación que otorga el voto en las elecciones. Asimismo, y a diferencia de organizaciones como los sindicatos o las corporaciones, no representan intereses de un sector en particular. "Las Organizaciones de la Sociedad Civil — OSC — dicen ser actores privados que defienden intereses públicos como el medio ambiente, la igualdad de géneros, los derechos del niño, etc.” (González y Villar, 2005, p. 2). 
En cuanto a la incidencia, o sostenibilidad social, esta se relaciona, en primer lugar, con el impacto generado a partir del objeto social que lleva a cabo la organización, y en segundo lugar, con la generación de redes, las cuales, en las organizaciones comunitarias, son vitales para trascender su objeto social. Las respuestas otorgadas por las organizaciones ratifican la importancia que tienen las redes para el adecuado funcionamiento, en tanto posibilita la gestión, no solo de recursos económicos, sino también de otra índole, recursos vitales para generar sostenibilidad y credibilidad a la entidad.

La comunicación es parte esencial de una organización comunitaria, ya que facilita que sus integrantes estén enterados de las actividades, así como la comunidad en general; para ello las organizaciones utilizan las redes sociales, volantes, carteles.

La comunicación se constituye como el puente y vehículo para la concientización y el empoderamiento, en donde importa más la militancia como proceso de búsqueda que la adhesión. El centro de su práctica es la perspectiva política. Este tipo de comunicación se vincula a una construcción colectiva entre los sujetos movilizados por alguna demanda, de significar y significarse como un sector con iniciativas respecto de algún tema bajo determinadas condiciones históricas, sociales y políticas. La comunicación pasa a ser constitutiva del colectivo humano que en nuestro caso reclama ante el poder político. La comunicación es el sostén de los acuerdos que se alcancen, es la que permite ir al encuentro con el otro, comprenderse, aceptarse y convivir en la diferencia (Carlosena, 2015, p. 8).

La comunicación, entonces, genera en las organizaciones identidad, apropiación y sentido de comunidad; por ello, sus estrategias comunicativas van desde la implementación de plataformas virtuales hasta el perifoneo barrial, todo enfocado a que las personas participen activamente de las propuestas de la organización comunitaria.

Aunado a lo anterior, es pertinente hacer énfasis en la participación que ejercen las organizaciones sociales y comunitarias, las cuales requieren de dos factores de gran relevancia: la voluntad de las instituciones públicas y de gobierno para brindar espacios y condiciones necesarias para la participación y la existencia de ciudadanos y organizaciones sociales que hagan uso de esos espacios, traducidos en acciones encaminadas a democratizar y cualificar los resultados de la gestión pública (Velásquez y González citado en Vivas et al., 2003). 
En este sentido, se puede afirmar que la participación de las organizaciones sociales de la Comuna 11 se ha reducido a acciones aisladas, sin que estas generen incidencia en la agenda pública y sin que se encuentren enmarcadas en la confrontación de dos aspectos importantes: "el dominio de las relaciones estado y sociedad, entre la participación y el autoritarismo 'participación-autoritarismo';[...] el dominio de los propósitos entre ciudadanía y anomia "ciudadanía-anomia"” (Vivas et al., 2015a, p. 83). Son estos aspectos en tensión los que limitan el accionar y trabajo conjunto entre el Estado y la sociedad civil.

De igual manera, es importante señalar que en el proceso investigativo se evidenció una débil articulación con otras instituciones, así como la precaria participación en los programas y proyectos de carácter municipal y territorial; en este último ítem se denotan tres variables importantes: la primera asociada al desconocimiento de los planes de desarrollo municipal, y por ende su ausencia de participación en los mismos, la segunda hace alusión al conocimiento de los planes, pero que no necesariamente implican la participación en ellos, y la tercera referente a aquellas que pese a su conocimiento y participación en dichos planes no acceden a ningún programa que se desligue de los mismos.

En tal sentido, se develó, en el proceso investigativo, que la incidencia de las organizaciones permanece en el ámbito micro, hecho que se encuentra estrechamente ligado a la poca credibilidad en la institucionalidad y a la débil articulación con otros grupos de interés, "no hay en las agendas de las organizaciones un objetivo común de construir alianzas, articulaciones, estrategias de trabajo conjunto, más allá de la coyuntura" (s. d.), por lo que se hace evidente la necesidad de fortalecer la articulación institucional y de alianzas público-privadas que permitan ampliar su campo de acción.

En los procesos participativos, llevados a cabo por las organizaciones, se pudieron delimitar problemáticas sociales que se encuentran sujetas a factores como la precariedad económica de la población, asociadas a su vez con la escasez de empleo, la presencia de actores armados, la falencia en el aspecto educativo, las problemáticas en temas de infraestructura vial, la poca apropiación de los espacios, los problemas de convivencia en la comunidad, la intolerancia, la falta de acompañamiento a la población infantil y juvenil y la marginalización de la participación de la población juvenil en el aspecto comunitario. También es importante mencionar que hay problemáticas a nivel interno como falta de financiación, de apoyo institucional y poca participación de los integrantes en algunos procesos formativos. 
Desde esta perspectiva, y contemplando las problemáticas sociales de las organizaciones, es importante volver sobre el sentido teleológico de las mismas, y que se encuentran precisamente relacionadas con dichas problemáticas bajo una connotación de interés colectivo asociado a la esfera de lo público:

La esfera pública es un espacio temático de conformación y acción de las organizaciones sociales que participan para agenciar sus problemas de manera que se conviertan en cuestiones públicas que se incluyan en agendas políticas; además, la esfera pública es el espacio de argumentación y deliberación sobre el alcance y sentido de la intervención pública (Vivas et al., 2015a, p. 79).

Dicho lo anterior, es pertinente señalar que la participación de las organizaciones también se orienta al seguimiento de las políticas públicas, teniendo en cuenta que "la responsabilidad de los problemas públicos no es exclusiva del Estado" (Vivas et al., 2015b, p. 157); es por tanto la veeduría ciudadana otro mecanismo de participación mediante el cual las organizaciones agencian el cumplimiento de los planes, programas y proyectos enfocados al desarrollo comunitario, que contribuye a la transformación positiva de las realidades y problemáticas que afrontan las mismas; sin embargo, el ejercicio investigativo dio cuenta de la poca veeduría a los procesos, debido al debilitamiento de la articulación institucional y de la participación asociativa.

Dado lo anterior, es de vital importancia la comprensión y el fortalecimiento de la organización comunitaria en relación con la formación política, el trabajo en red, el empoderamiento de sus objetivos y metas comunes que llevan a una mayor participación, tanto en el ámbito interno como en la esfera pública; en este último aspecto Villar expone algunas fases en las que las organizaciones sociales han incidido en este ámbito, siendo estas: "La colaboración y el diálogo sobre políticas con el gobierno; la participación en la gestión de servicios públicos; el control y veeduría de programas públicos; y la amplia participación en la deliberación sobre asuntos de interés público" (s. d.); con esto, hay que considerar que la individualización y la marginalización de ciertos sectores - como es el caso de la participación juvenil en torno a lo comunitario evidenciada en la investigación - genera rechazo hacia la intervención política, dado los imaginarios y la forma en la que esta se ha ejercido, mediante métodos clientelistas que dividen los liderazgos en torno a la obtención de dádivas que favorecen a un determinado individuo, o a un grupo selecto: 
El panorama dejaba entrever un abismo entre el ciudadano y la esfera pública en cuanto a la participación, pues no ha habido una firme confianza frente al político o la política misma. Asimismo, la participación podía llegar a asociarse a la participación en política, dejando como producto un estigma negativo, gracias a otro tipo de factores como la presencia de un fuerte corporativismo e individualismo en la política, que no contribuyen a fortalecer la participación (Vivas et al., 2015, p. 80).

Desde esta perspectiva, el individualismo centrado en fines particulares es un factor dañino a los procesos colaborativos y de construcción comunitaria, como se denota en la afirmación de uno de los líderes: "Es necesario capacitar a los muchachos en el tema de participación, nos sentimos excluidos [...] acá los lideres cada uno trabaja por su lado, deseamos articularnos, vincular estrategias que nos permitan llegar a los barrios" (entrevista personal con líder del grupo Juventud en Red, s. d.). Dado lo anterior, es pertinente señalar que las organizaciones son conscientes de la importancia del trabajo en red; sin embargo, algunas presentan falencias en aspectos formativos, organizativos y de empoderamiento de liderazgos que limitan su incidencia en otras esferas de la sociedad.

En este sentido, se puede afirmar que, con una adecuada articulación e intercambio de saberes desde los diferentes ámbitos en los que operan las organizaciones sociales y comunitarias, se puede obtener un mayor impacto, tejiendo redes de trabajo que contribuyan al bienestar y desarrollo colectivo.

\section{LA INVESTIGACIÓN Y LA ARTICULACIÓN CON LA PRAXEOLOGÍA}

La generación de conocimiento es una de las responsabilidades de las Instituciones de Educación Superior, y que dicho conocimiento sea pertinente a las necesidades del contexto es de vital importancia, pues posibilita la transformación de la sociedad. Por ello, la articulación entre teoría y práctica resulta siendo el insumo significativo para materializar la praxeología, ya que esta "aparece como un esfuerzo de hermenéutica práctica que articula las funciones universitarias de investigación, de compromiso social crítico y de formación profesional al interior de un contexto pluridisciplinario" (Juliao, 2011, p. 13).

De esta manera, entonces, se comprueba la pertinencia de la investigación llevada a cabo, en la medida que posibilita dos asuntos vitales en la academia: 
- La articulación teoría y práctica (praxeología)

- La proyección social

Frente al primer ítem se retoma lo que plantea Juliao (2011):

El quehacer praxeológico es un análisis que parte de la experiencia de los propios protagonistas (quienes avanzan hacia reflexiones práxicas), que implica trabajar individual y grupalmente en tiempos y espacios adecuados, como provocación y desafío para un aprendizaje desde la cotidianidad (p. 17).

Es así como la investigación de las organizaciones sociales y comunitarias de la Comuna 11 surge por una necesidad, del Programa de Trabajo Social, de evidenciar dichas organizaciones para caracterizarlas y observar cómo se lleva a cabo el biodesarrollo, la organización y participación comunitaria, asuntos de suma importancia para el quehacer profesional. grupo: ${ }^{1}$

La investigación tuvo varios componentes que fueron vividos por el

- Reconocimiento del territorio: allí se pudo llevar a cabo una cartografía, técnica que es explicada en clase y que en el territorio se concreta a través de preguntas orientadoras y la observación participante.

- Formulación y aplicación de técnicas de recolección de información: se llevan a cabo dos técnicas, la entrevista, que fue implementada en aproximadamente catorce organizaciones y el grupo focal en ocho organizaciones. El grupo de investigación convocó a la comunidad, concertó tiempos, espacios y aprendió de los saberes populares.

- Análisis de la información: todo ese compendio de información se concretó en un informe que, posteriormente, fue llevado a la comunidad, para validar y complementar lo hallado.

Lo praxeológico como práctica investigativa procura así:

1 El grupo investigativo está compuesto por docentes y estudiantes del Programa de Trabajo Social. 
Entender la reflexión como acto mental, como praxis social y como visión crítica de la realidad en que se está y con la que se interactúa. Esta perspectiva supone no desatender el interés (la curiosidad, la motivación) que puede encauzar los procesos de observación y reflexión dado que estos se convierten en desencadenantes de genuina indagación, por parte del aprendiz, cuando se trata de una pedagogía praxeológica (Juliao, 2013, p. 69).

Dicho lo anterior, de la interacción de lo teórico con lo práctico surge un conocimiento renovado y pertinente, dado que si bien el objeto inicial de la investigación fue caracterizar las organizaciones sociales y comunitarias para develar sus aportes al desarrollo y a los procesos de participación, se desprenden otras propuestas enfocadas a la intervención, que dan pie al segundo ítem antes mencionado, que es la proyección social.

La proyección social, deber de la universidad, máxime en la UNIMINUTo que enfatiza en la transformación social como uno de sus pilares misionales, marca a partir de la investigación dos posibles acciones que concretarían la proyección social, de cara al beneficio mutuo, comunidad-academia.

El primero enfocado en la articulación de varios cursos del pénsum del Programa de Trabajo Social; el segundo dirigido al fortalecimiento de los procesos de práctica social y profesional. Frente a la articulación pénsum-contexto la comunidad nombra dicha estrategia "llevar la universidad a la calle". Ello porque encuentran una relevante necesidad de que la academia le devuelva a la calle su sentido; es decir, la calle como laboratorio de aprendizaje, y donde tanto los jóvenes como la comunidad en general sientan que el territorio es posible de recorrer, de que la esquina es un lugar para el encuentro y de que existe la posibilidad de transformar un contexto violento por uno más amigable, sobre todo para los jóvenes.

Llevar la universidad a la calle es dotar a la comunidad de unas estrategias que renueven sus capacidades, y a la universidad, es decir, a la academia, le concede una dosis de realidad que la toca y dinamiza su claustro, espacio que muchas veces se vuelve indiferente y descontextualizado de lo que realmente pasa.

En el segundo foco, que es el fortalecimiento de las prácticas sociales y profesionales, la universidad recibe un llamado de la comunidad, ya que le pide que genere continuidad; en ese sentido, demanda un proceso sostenible, donde cada persona que pase deje una sistematización de lo que hace y de lo que queda pendiente, con el fin de generar continuidad. 
La comunidad no desea ser vista por la academia como un objeto, sino como un sujeto activo que tiene un saber popular que la universidad puede y debe aprovechar para que realmente comprenda el contexto y logre transformarlo.

La praxeología, tanto en el contexto académico como en el comunitario, es un enfoque pedagógico idóneo para hacer que el conocimiento salga del claustro e impacte de forma real y pertinente los procesos de la comunidad; en este caso concreto, las causas organizativas y participativas del contexto aledaño a UNIMINUTO.

\section{REFERENCIAS}

Alcaldía de Bello (2009). Revisión y Ajuste del Plan de Ordenamiento Territorial (POT). Acuerdo 033. Recuperado de http://www.metropol.gov. co/observatorio/Expedientes\%20Municipales/Bello/Documentos\%20tematicos/POT\%20Bello\%202009\%20Acuerdo\%20033.pdf

Alcaldía de Bello (2012). Plan de Desarrollo Municipal: Bello Ciudad Educada y Competitiva. Recuperado de http://cdim.esap.edu.co/BancoMedios/Documentos\%20PDF/bello.pdf

Alcaldía de Bello (2013). Encuesta Calidad de vida Valle de Aburrá. S. d.

Alcaldía de Bello (2015). Plan Municipal de Gestión de riesgos y desastres. Recuperado de http://www.bello.gov.co/index.php/features/nuestros-planes/item/77-plan-municipal-de-gestion-del-riesgo

Alcaldía de Bello (2016). Plan de Desarrollo Municipal: Bello, ciudad de Progreso. Recuperado de http://www.siipe.co/wp-content/ uploads/2014/08/Plan-de-Desarrollo-Bello-2016-2019.pdf

Bedoya, I., y González, C. (2008). El empoderamiento comunitario para la construcción de territorios saludables. Tendencias y Retos, (13), 185-200.

Carlosena, M. (2015). La comunicación en las organizaciones sociales y sus posibilidades de incidencia en la esfera del poder. Recuperado de http://www.alaic2015.eci.unc.edu.ar/files/ALAIC/EJE12/alaic_12_-13.pdf

Cruz, L., Hernández, S., Llano, L. A., López, Z., Pinzón, O., y Rodríguez, A. (2008). Factores internos y externos que inciden en la sostenibilidad de organizaciones comunitarias de base en la localidad de Ciudad Bolivar [tesis de grado, Facultad de Ciencias Económicas y Sociales]. Universidad de La Salle, Bogotá, Colombia. Recuperado de http://repository.lasalle.edu.co/ bitstream/handle/10185/1949/T93.08\%20C889f.pdf?sequence=1 
Delgado, O. (1971). Organización y participación de los campesinos en las políticas de desarrollo rural en América Latina. Washington: Secretaría General de la Organización de Estados Americanos - Departamento de Asuntos Sociales

González, I., y Villar, R. (2005). Organizaciones de la sociedad civil e incidencia en políticas públicas. Buenos Aires: Colección Gestión Social.

Juliao, C. (2011). El enfoque praxeológico. Bogotá: Corporación Universitaria Minuto de Dios.

Juliao, G. (2013). Una pedagogía praxeológica. Bogotá: Corporación Universitaria Minuto de Dios.

Loaiza, J. F. (2017). Definida terna para alcaldía de Bello. Recuperado de http://www.elcolombiano.com/cronologia/noticias/meta/administracionpublica

Maldonado, C. (2012). Bioeconomía y biodesarrollo. Recuperado de http://www.eldiplo.info/portal/index.php/1851/itemlist/tag/biodesarrollo

Michaels, N. (2010). Las fiestas populares de San Pacho en Quibdó (Chocó, Colombia) como herramienta de organización comunitaria. Trabajo Social, (12), 167-180.

Municipio de Bello (2015). Consejo Municipal para la Gestión del Riesgo de Desastres. CMGRD. Plan Municipal de Gestión Riesgo de Desastres de Bello. Recuperado de www.bello.gov.co/index.php/features/.../100_ 686490b6ace77551d0a28bff573621bd

Sandoval, C. (2002). Investigación cualitativa. Módulo Cuatro. Bogotá: ARFO.

Soto, G. (2016). De Zamora a Bethania una Casa llena de Historia. La Bitácora, 1-22.

Valencia, J. F., y Galeano, M. (2011). Historia de las organizaciones sociales de base. Revista Kavilando, (3), 60-65.

Vargas, G. (2012). Espacio y territorio en el análisis geográfico. Reflexiones, 91(1), 313-326. Recuperado de http://www.redalyc.org/ pdf/729/72923937025.pdf

Vivas, O., Sarmiento, J., y González, J. (2015). Un aporte al estudio de las formas de organización social desde la orilla de la participación política en Colombia. Cuadernos Latinoamericanos de Administración, 75-92. Recuperado de http://revistas.unbosque.edu.co/index.php/cuaderlam/article/ view/1621/1223

Vivas, O., Gómez, J., y González, J. (2015a). Informe de la investigación "Fundamentación de la línea de investigación académica sobre las 
El enfoque praxeológico, articulación entre conocimiento, práctica y transformación social

formas organizativas de agenciamiento colaborativo de problemas de grupos vulnerables 2014-2015”. Medellín, Colombia: Corporación Universitaria Americana - CORUNIAMERICANA.

Vivas, O., Goméz, J., y González, J. (2015b). Una aproximación al papel de las organizaciones y su incidencia en el desarollo y el ejercicio de las libertades. Equidad y Desarrollo, (24), 139-163. Recuperado de https:// dialnet.unirioja.es/servlet/articulo?codigo $=5262309$ 